\title{
A training sequence parallel detection technology based on timeslot sliding window
}

\author{
Jian Shi ${ }^{1}$, Jianfeng Huang ${ }^{2^{*}}$ and Kaihua Liu
}

\begin{abstract}
The Global System for Mobile communication (GSM) radio network's latest development status and its prominent interference problems were discussed. The limitations of the cellular radio network analysis using the traditional drive test and frequency scanning technology were discussed, which led to the inaccurate interference location and inefficient interference optimization. A new training sequence parallel detection technology base on timeslot sliding window was proposed. The timeslot sliding window mechanism and the training sequence parallel correlative detection algorithms were discussed in detail, and the advantage of these technologies was discussed though comparative analysis. With the successful application cases of the engineering practice in Zhejiang Province of China, the important value of the new technology proposed in this paper in the radio network planning and optimization engineering applications was proved.
\end{abstract}

Keywords: Timeslot sliding window; Training sequence; Parallel detection; Cellular radio network

\section{Introduction}

With high growth of mobile communication business, the load of Global System for Mobile communication (GSM) radio network increases daily. The frequency bands of GSM900, DCS1800, and EGSM have been massively implemented. The number of sites with high carrier configuration and density of frequency reuse increase constantly while the distance between base stations of cellular networks is decreasing. At present, the GSM radio network of China Mobile Communications Corporation has widespread problems of excessive overlapping coverage, severe cross-boundary coverage, and rapidly increasing probability of co-channel interference (CCI) and adjacent channel interference (ACI), which led to radio signal quality's degrading, the mobile stations' (MS) reception (Rx)-Quality level 5 to 7 (received signal quality, range from level 0 to 7 , level 0 to 4 indicates good radio signal quality and level 5 to 7 indicates poor radio signal quality) proportion's significant increasing, and user perception's obvious declining [1].

Analytical methods [2-4] of traditional regular hexagon cell clusters for interference and coverage cannot

\footnotetext{
* Correspondence: jhuang@163.com

${ }^{2}$ School of Telecommunications Engineering, Beijing University of Posts and Telecommunications, Beijing 100876, China

Full list of author information is available at the end of the article
}

meet the requirement of increasing complexity of radio network analysis. Moreover, traditional regular testing methods including drive test and frequency scanning test cannot locate specific interfered frequency, interference levels of serving cell, and the location of interference source cell, which becomes a technical bottleneck for further detailed optimization of current radio network.

Traditional Broadcast Channel (BCCH) frequency scanning data is common measuring data source of present integral network structure assessment including coverage and interference [1], which can accurately reflect the radio signal coverage status of $\mathrm{BCCH}$ frequency [5]. There are researches on the traditional $\mathrm{BCCH}$ carrier frequency scanning technique, such as the literature [6,7]. However, traditional frequency scanning devices can only measure and decode $\mathrm{BCCH}$ channel without effectively distinguishing and measuring received power of the same traffic channel (TCH) carrier frequency coming from different cells.

Under normal circumstances, $\mathrm{BCCH}$ carrier frequency is full-power transmitted in normal working condition of each cell while the transmitting power of TCH frequency is influenced by factors of frequency hopping, discontinuous transmission (DTX), power control, etc.; in addition, $\mathrm{BCCH}$ frequency and $\mathrm{TCH}$ frequency have different reuse densities, so there is a large difference between the system noise floor levels of two types of carrier frequency. In 
different regions (grids) of cells, the received power, carrier interference ratio $(\mathrm{C} / \mathrm{I})$, and noise floor level of $\mathrm{BCCH}$ and $\mathrm{TCH}$ carrier frequency certainly have differences.

Hence, improving accurate frequency scanning measurement for $\mathrm{TCH}$ frequency besides $\mathrm{BCCH}$ frequency scanning measurement no doubt has significant engineering application value for radio network problems' analysis and optimization.

It is very important for exploring the new measuring technical means and corresponding analysis methods to tap the radio network performance potential fundamentally. First, new measuring technology should be researched to measure the radio network more efficiently and sufficiently; second, new measurement data analysis method should be researched to analyze the massive measurement data more scientifically and accurately. Thus, more precise problem location and optimization solution could be gotten to improve and upgrade the overall performance of the radio network sufficiently.

A kind of new whole-band and high-accuracy traffic timeslot scanning technology is proposed in this paper - a training sequence parallel detection technology base on timeslot sliding window. According to the distribution of different training sequence codes that are obtained from each cell of radio network, it can distinguish and measure received power, C/I, and noise floor of co-channel frequency coming from different co-channel cells in radio networks ${ }^{\mathrm{a}}$. It supplies new frequency scanning measurement and scientific analysis methods for accurate positioning and optimization solution of radio network interference and coverage problems $\mathrm{s}^{\mathrm{b}}$.

The research on training sequence detection in the industry mostly focuses on the channel estimation, synchronization maintenance, and power measurement inner mobile communication system, as reflected in the literature [8-10]. The frequency scanning measurement based on the training sequence detection and its corresponding analysis techniques outside the system, as a new application direction, has little relevant research literature.

\section{Timeslot measuring frequency scanning technology}

\subsection{Necessity of timeslot measurement}

The high-precision timeslot measuring frequency scanning proposed in this paper can perform accurate measurement of each traffic timeslot signal power for each frequency in whole-band in period of full-frame for both $\mathrm{BCCH}$ and $\mathrm{TCH}$ carrier frequency, which is an innovative radio network measuring technique method in the present industry. In different test areas, it can accurately measure the received power level and $\mathrm{C} / \mathrm{I}$ in different timeslots of each carrier frequency from different overlapping coverage cochannel cells associated with the training sequence code (TSC) allocation for each cell in the radio network. So, this new measuring technique method can be supplied for the depth profiling of cellular radio network coverage and interference.

Scanning per timeslot for each carrier frequency can effectively distinguish each timeslot's idle state and traffic state: in the idle state of timeslot, the corresponding correlative power of all training sequence code $\mathrm{C} / \mathrm{I}$ is less than $0(\mathrm{C} / \mathrm{I}<0)$ where the timeslot power reflects the noise floor of radio networks, so the measuring in the idle state of timeslot supplies more fine grid's accurate measuring data source and new analysis methods for more precise estimation of noise floor; in the traffic state of timeslot, the corresponding correlative power of all training sequence code $\mathrm{C} / \mathrm{I}$ is larger than $0(\mathrm{C} / \mathrm{I}>0)$ under normal conditions, so whether the carrier power comes from serving cells or interference cells can be decided according to training sequence allocation. It offers the most scientifically objective accurate measuring data for carrier coverage and interference problems analysis.

\subsection{Principle of timeslot measuring technique}

The time slot is a time interval of $576.9 \mu \mathrm{s}(15 / 26 \mathrm{~ms})$, that is 156.25 bit durations, and its physical content is called a burst. Four different types of bursts exist in the system. Structure of these bursts appears in Figure 1 [11].

The most traffic in GSM is carried by normal burst (NB). NB is used to carry information on traffic and control channels, except for Random Access Channel (RACH). It contains 116 encrypted bits and includes a guard time of 8.25 bit durations $(30.46 \mu \mathrm{s})$.

GSM defines nine groups of training sequence code (TSC) [12] for NB; eight groups of which are used for the cell traffic channel. The remaining group is used for transmitting signal power filling of $\mathrm{BCCH}$ carrier frequency dummy burst, which is shown in Expression (1).

Training bits $=$

$[0,0,1,0,0,1,0,1,1,1,0,0,0,0,1,0,0,0,1,0,0,1,0,1,1,1$; $0,0,1,0,1,1,0,1,1,1,0,1,1,1,1,0,0,0,1,0,1,1,0,1,1,1$; $0,1,0,0,0,0,1,1,1,0,1,1,1,0,1,0,0,1,0,0,0,0,1,1,1,0$; $0,1,0,0,0,1,1,1,1,0,1,1,0,1,0,0,0,1,0,0,0,1,1,1,1,0$; $0,0,0,1,1,0,1,0,1,1,1,0,0,1,0,0,0,0,0,1,1,0,1,0,1,1$; $0,1,0,0,1,1,1,0,1,0,1,1,0,0,0,0,0,1,0,0,1,1,1,0,1,0$; $1,0,1,0,0,1,1,1,1,1,0,1,1,0,0,0,1,0,1,0,0,1,1,1,1,1$; $1,1,1,0,1,1,1,1,0,0,0,1,0,0,1,0,1,1,1,0,1,1,1,1,0,0$; \%above 8 is for the TCH

$0,1,1,1,0,0,0,1,0,1,1,1,0,0,0,1,0,1,1,1,0,0,0,1,0,1$ $\%$ dummy burst];

The three least significant bits of the Base Station Identification Code (BSIC) indicate which of the eight training sequences is used in the bursts sent on the downlink common channels of the cell [13]. The training sequence known as reference signal is used for the channel equalization in time domain when receiving signals for each cell, so that it can improve the anti-interference ability of GSM mobile communication system. 


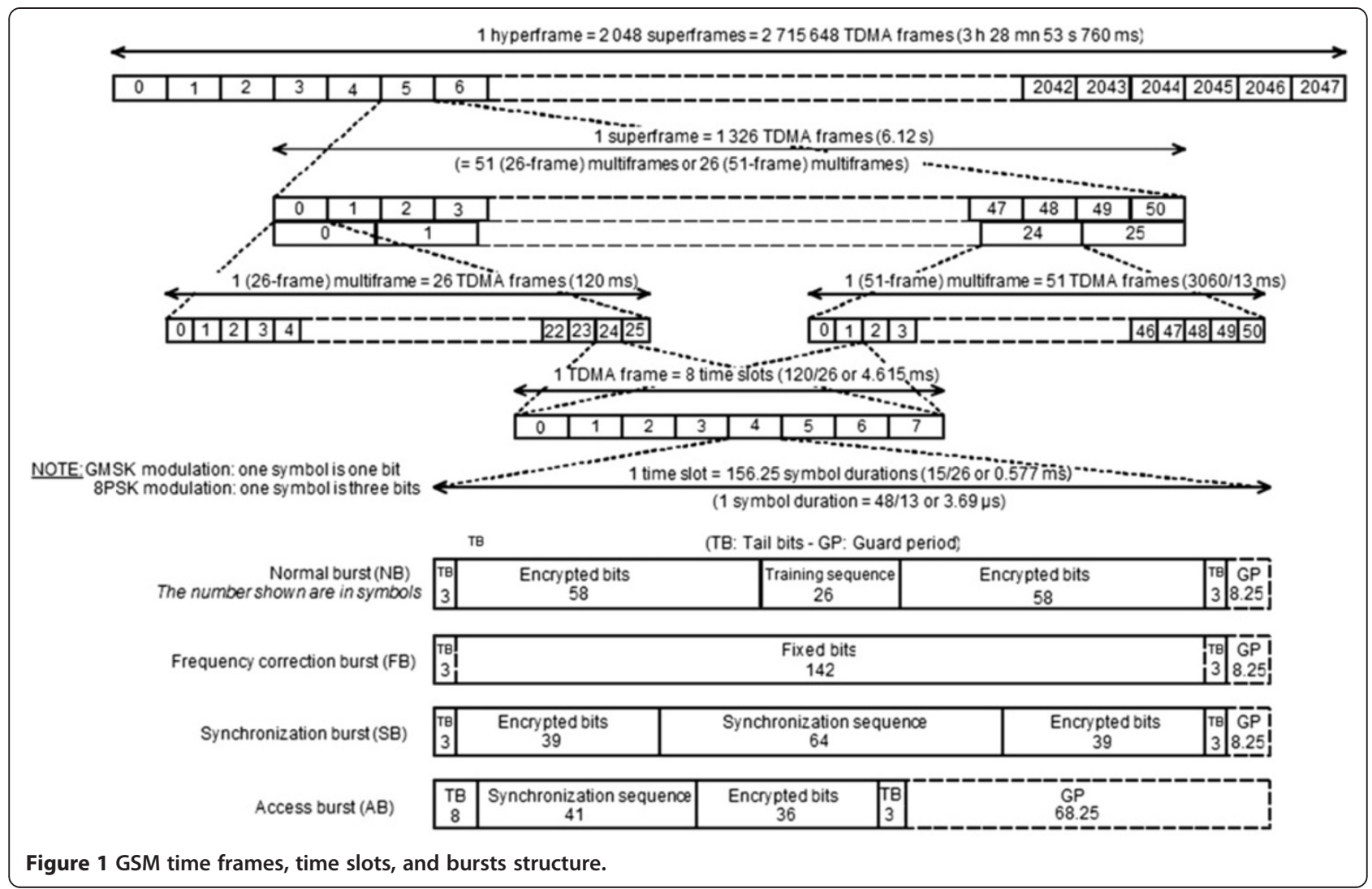

The downlink timeslot signal of different cells using the same carrier frequency can use different training sequences to make the distinction. This supplies an effective technical method for the distinguishing of interference signal power between different cells.

High-accuracy traffic timeslot scanning measurement provides accurate measurement for carrier timeslot sequence's power and $\mathrm{C} / \mathrm{I}$ in the time dimension besides measures all carriers in frequency dimension.

The core of high-accuracy timeslot measuring technique is to perform signal sampling over one frame period (eight timeslots) for every carrier frequency. Taking into account the lack of orthogonal property between nine training sequence codes, training sequence parallel detection technology base on timeslot sliding window proposed in this paper is used for every timeslot sampled signal detection, and performing the correlative power detection of nine training sequence codes can accurately measure the maximum correlative power and $\mathrm{C} / \mathrm{I}$ and detect corresponding TSC of training sequence code block for each timeslot.

\section{Timeslot sliding window parallel detection technology}

3.1 Timeslot sliding window parallel detection

In consideration of GSM as an asynchronous system, downlink signals between each base station do not perform timeslot synchronization. The boundary of each timeslot would not coincide in one physical frame period in the received sampled signal of the same carrier coming from different cells. Hence, the detection for every timeslot power must perform sliding widow detection in a burst over one timeslot period. Moreover, parallel detecting using nine groups of training sequence code for every time-delay signal is to detect whether this timeslot exists in traffic occupancy and also to detect the corresponding training sequence code of maximum correlative power signal when timeslot is existing in traffic occupancy. Figure 1 shows the parallel sliding window time slot detection technology method.

The parallel detection sliding window that Figure 2 shows consists of 21 delayers. Time delay period of every delayer $T$ is $1 \mu \mathrm{s}(T=1 \mu \mathrm{s})$. The whole length of sliding window that is extended for $10 \mu$ s to both sides from central point is totally $21 \mu \mathrm{s}$. The sampled signal delayed every time is performed parallel correlative detection with nine groups of training sequence codes.

The GSM training sequence codes have a duration of 26 Gaussian minimum shift keying (GMSK) symbols, which is equal to $(26 / 156.25) \times 577=96 \mu \mathrm{s}$; experience shows that $20 \%$ of signal duration used in sliding window could ensure the effective signal detection. So, there are a total of 21 delayers in the proposed training 


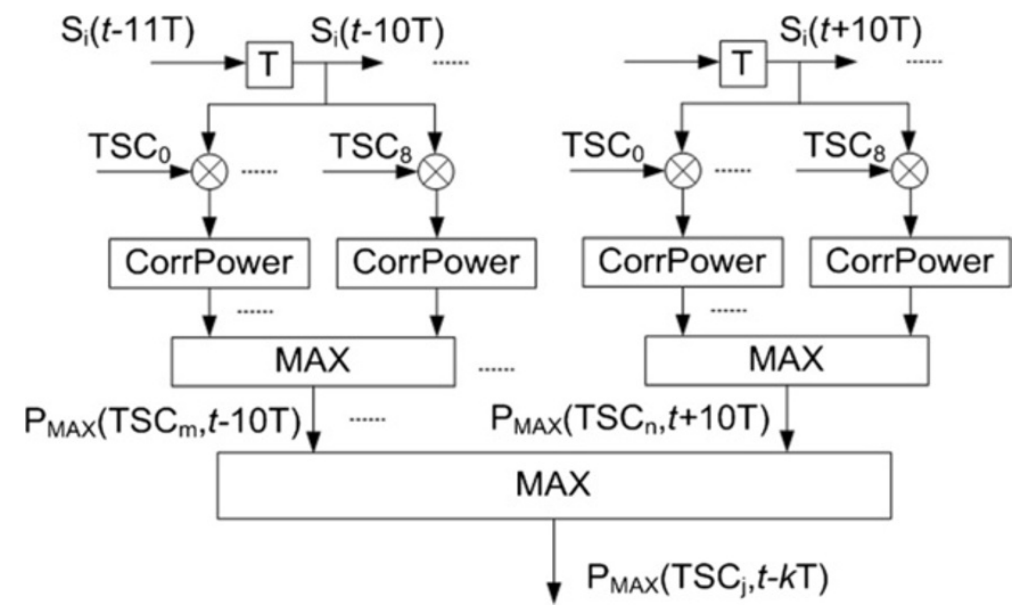

Figure 2 Training sequence code parallel detection timeslot sliding window.

sequence detection method, and each delayer has $1 \mu \mathrm{s}$ time delay.

Five bits at the beginning and 5 bits at the end that are from training sequence of 26 bits for each group are obtained by 16 bits (located in the center point) original sequence's performing period expanding, so there will be both 5 zero points on both sides of correlative peak value when using 16 original bits to perform correlative detecting for transmitted timeslot signal of the cell.

It totally needs 21 parallel strongest training sequence code correlative power detections in all for the measuring of a timeslot.

\subsection{Timeslot power detection}

Timeslot power detection mainly contains timeslot training sequence maximum correlative power detection, timeslot mean power detection, and timeslot noise floor power detection.

Timeslot training sequence code maximum correlative power detection is to detect the maximum training sequence code correlative power and $\mathrm{C} / \mathrm{I}$ in one timeslot period. If one timeslot $\mathrm{SLOT}_{u}$ of carrier frequency $f_{p}$ is occupied by the traffic of serving cell CELL (means the $h$ th cell in the radio network, which is allocated with $l$ th training sequence code $\left.\mathrm{TSC}_{l}, 0 \leq l \leq 8\right)$ in the specified test zone (grid) $g_{q}$ (means the $q$ th grid in the cellular radio network, $0 \leq q \leq Q$, on the assumption that the cellular radio network is divided into $Q$ grids) and in the test time $t, \mathrm{TSC}_{l}$ 's maximum correlative power $P_{\text {corrMAX }}\left(\mathrm{SLOT}_{u}, \mathrm{TSC}_{l}, t-k \mathrm{~T}\right)$ and $\mathrm{C} / \mathrm{I}$ from cell $\mathrm{CELL}_{h}$ (means the $h$ th cell in the cellular radio network, $0 \leq h \leq H$, on the assumption that there are $H$ cells in the cellular radio network) can be detected. The algorithm of $P_{\text {corrmax }}\left(\mathrm{SLOT}_{u}, \mathrm{TSC}_{l}, t-k \mathrm{~T}\right)$ is expressed as Equation (2).

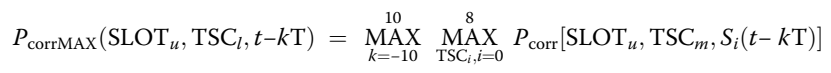

where the symbol $\operatorname{MAX}(\cdot)$ means the max value of array element within parentheses is obtained. $\mathrm{SLOT}_{u}$ means the $u$ th timeslot in one frame, $0 \leq u \leq 7$. The algorithm of training sequence code maximum correlative power in one frame $P_{c o r r m a x}^{F}$ is expressed as Equation (3).

$$
P_{\text {corrMAX }}^{F}=\underset{\operatorname{SLOT}_{u}, u=0}{\stackrel{7}{M}} \underset{k=-10}{\stackrel{10}{M A X}} \underset{\operatorname{TSC}_{i}, i=0}{\stackrel{8}{\mathrm{M}}} P_{\text {corr }}\left[\mathrm{SLOT}_{u}, \mathrm{TSC}_{m}, S_{i}(t-k \mathrm{~T})\right]
$$

where $P_{\text {corrMAX }}^{F}=P_{\text {corrmax }}\left(\mathrm{FRAME}_{w}, \mathrm{SLOT}_{v}, \mathrm{TSC}_{l}, t-k \mathrm{~T}\right)$, and the FRAME ${ }_{w}$ means the $w$ th frame was measured.

The maximum training sequence code correlative power and the corresponding timeslot central point in one frame, eight timeslots, period is chosen as the detecting time reference of timeslot analytical timeslot central point in one frame period at this time. Moreover, each timeslot central point and timeslot boundaries' dividing in one frame period is performed based on this time reference. Figure 3 shows that the training sequence code correlative power received by $\mathrm{SLOT}_{3}$ is strongest within one frame period. The rest of timeslot central points and timeslot boundaries' positioning extension in the whole frame period is implemented based on the corresponding of peak time of training sequence code correlative power received by $\mathrm{SLOT}_{3}$ which is chosen as $\mathrm{SLOT}_{3}$ timeslot central point reference. In addition, each other timeslot's central and boundaries division and the maximum training sequence 


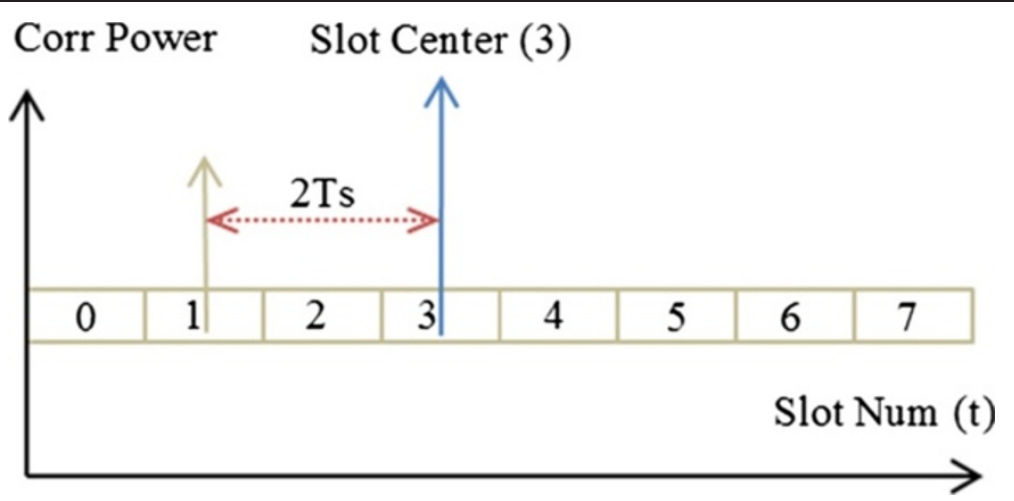

Figure 3 Positioning of timeslot central point.

code correlative peak power detection in one whole frame period are performed on this basis.

The algorithm of traffic occupancy timeslot $\mathrm{SLOT}_{\nu}$ 's timeslot mean received power $\bar{P}\left(\mathrm{SLOT}_{v}, t-k \mathrm{~T}\right)$ is expressed as Equation (4).

$$
\begin{aligned}
\bar{P}\left(\mathrm{SLOT}_{v}, t-k \mathrm{~T}\right)=\frac{1}{N} \sum_{n=0}^{N-1} & \left(\left|I_{S}\left(\mathrm{SLOT}_{v}, n, t-k \mathrm{~T}\right)\right|^{2}\right. \\
& \left.+\left|Q_{S}\left(\mathrm{SLOT}_{v}, n, t-k \mathrm{~T}\right)\right|^{2}\right)
\end{aligned}
$$

where $I_{S}\left(\mathrm{SLOT}_{v}, t-k \mathrm{~T}\right)$ and $Q_{S}\left(\mathrm{SLOT}_{v}, t-k \mathrm{~T}\right)$, respectively, are timeslot $\mathrm{SLOT}_{v}$ time periods' $I$ and $Q$ two-way base band complex signal of received sampled signal GSM modulating signal symbol series. $N$ is a $\mathrm{SN}$ modulating symbolic number in a timeslot period. And also $I_{S}$ $\left(\mathrm{SLOT}_{v}, t-k \mathrm{~T}\right)$ and $Q_{S}\left(\mathrm{SLOT}_{v}, t-k \mathrm{~T}\right)$ are given by

$$
I_{S}\left(\mathrm{SLOT}_{v}, t-k \mathrm{~T}\right)=\left\{I_{S}\left(\mathrm{SLOT}_{v}, n, t-k \mathrm{~T}\right), n=0,1,2, \ldots, N-1\right\}
$$

$$
Q_{S}\left(\mathrm{SLOT}_{v}, t-k \mathrm{~T}\right)=\left\{\mathrm{Q}_{S}\left(\mathrm{SLOT}_{v}, n, t-k \mathrm{~T}\right), n=0,1,2, \ldots, N-1\right\}
$$

\subsection{Timeslot $\mathrm{C} / \mathrm{I}$ detection}

The signal-to-noise ratio (SNR) CtoI(SLOT ${ }_{v}, t-k \mathrm{~T}$ ) of timeslot occupied by traffic can be calculated based on the measurement of $P_{\mathrm{MAX}}\left(\mathrm{SLOT}_{v}, \mathrm{TSC}_{l}, t-k \mathrm{~T}\right)$ and $\bar{P}$ $\left(\mathrm{SLOT}_{v}, t-k \mathrm{~T}\right)$, the algorithm of which is expressed as Equation (7).

\subsection{Timeslot noise floor detection}

For the vacant timeslot $\mathrm{SLOT}_{v}$ not occupied by traffic, the corresponding $\mathrm{C} / \mathrm{I}$ of detected training sequence code maximum correlative power is less than $0(\mathrm{C} / \mathrm{I}<0)$, where the timeslot detecting power is the noise floor of $f_{p}$ frequency's radio network. All the noise floor statistic of vacant timeslot in the specified test grid is mean noise floor of this carrier frequency $\bar{N}_{\text {floor }}\left(f_{p}, t-k \mathrm{~T}\right)$, the algorithm of which is expressed as Equation (8).

$$
\begin{aligned}
\bar{N}_{\text {floor }}\left(f_{p}, t-k \mathrm{~T}\right)= & \frac{1}{\operatorname{count}\left[v, \operatorname{CtoI}\left(\mathrm{SLOT}_{v}, t-k \mathrm{~T}\right)<0\right]} \\
& \times \sum_{v=0, \mathrm{CtoI}\left(\mathrm{SLOT}_{v}, t-k \mathrm{~T}\right)<0}^{7} \bar{P}\left(\mathrm{SLOT}_{v}, t-k \mathrm{~T}\right)
\end{aligned}
$$

where count $\left[v, \mathrm{CtoI}\left(\mathrm{SLOT}_{v}, t-k \mathrm{~T}\right)<0\right]$ is the timeslot number of CtoI $<0$ in Equation (8). $\bar{N}_{\text {floor }}\left(f_{p}, t-k \mathrm{~T}\right)$ is mean noise floor in one frame period. In the practical application, the statistical averaging of noise floor for several frame periods of several test loops from the same carrier frequency in specified test grid can be performed. It can increase effective signal's sampling quantity of the vacant timeslot to eliminate the effect brought by signal rapid fading, so that the mean value of noise floor can reflect the real situation of radio networks more accurately.

\subsection{The advantage of the timeslot measurement}

At present, the industry of traditional frequency scanner can only measure the $\mathrm{BCCH}$ frequency and the Received Signal Strength Indication (RSSI) of TCH carrier frequency and cannot distinguish and measure the co-channel $\mathrm{TCH}$

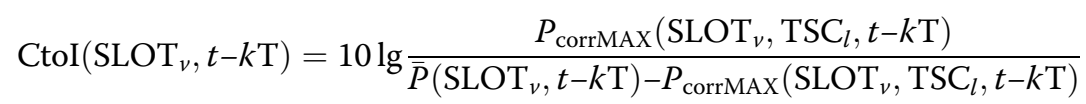


carrier signal from different overlaying coverage cells, which has great limitation to effectively analyze and accurately locate wireless network problems. The literature [1] describes the algorithm theory and its application for wireless network analysis based on the presumption that traditional $\mathrm{BCCH}$ carrier frequency measurement equivalent to $\mathrm{TCH}$ carrier frequency measurement in one cell. Its shortcomings are mainly in the following two aspects: first, it cannot accurately reflect the transmission power differences between $\mathrm{BCCH}$ and $\mathrm{TCH}$ the carrier TRX in radio network, which may come from the power control or RF hardware performance difference; and second, it cannot reflect the TCH carrier frequency traffic correlation between the different overlaying coverage cells. All these become the root causes that the interference source cannot be accurately located in current cellular wireless network optimization engineering.

Assuming that the analyzed GSM radio network area is in a dense traffic urban area, which has $N$ overlaying coverage cells, $M$ carrier frequencies could be reused, each cell has $L$ carrier frequency TRXs on average. When $N \times L>M+k, k \geq 2$, then there must be at least $k$ co-channel interference cell pairs according to the traditional analysis presumption that $\mathrm{TCH}$ carrier frequency power level measurement results are equaled to $\mathrm{BCCH}$ carrier frequency scanning measurement results. With traditional frequency scanning measurement technology, it cannot distinguish and measure the co-channel TCH carrier signal from different overlaying coverage cells in a specific observation period; it also cannot measure the TCH traffic correlation between them, so it cannot locate whether co-channel interference happens among co-channel cell pair, in which co-channel cell pair the cochannel pair co-channel interference happen, which co-channel cell pair has the most severe co-channel interference, and also could not choose the best carrier frequency to the adjustment and optimization of the interfered carrier frequencies.

In the case of traffic occupation, such as in the GSM radio network's busy traffic time, the $\mathrm{TCH}$ carrier frequencies' co-channel power from different overlaying coverage cells could be distinguished and measured directly with the training sequence parallel detection technology base on timeslot sliding window proposed in this paper, by which it could locate the co-channel interference among overlaying coverage cells precisely. Furthermore, though all-band frequency scanning measurement parallelly detects all the training sequences' power level in each timeslot in the measurement frame period, the carrier frequencies with low reuse density, low traffic, and low noise floor could be chosen to the adjustment and optimization of the interfered carrier frequencies. In these ways, the performance of the radio network could be fully enhanced.
The advantage of the training sequence parallel detection technology base on timeslot sliding window proposed in this paper is proved through the above comparative analysis, which could fundamentally overcome the problems induced by traditional frequency scanning measurement and its interference analysis presumption - $\mathrm{TCH}$ carrier frequency power level equaled to $\mathrm{BCCH}$ carrier frequency power level. The GSM cellular radio network's coverage, interference, network structure, and frequency plan could be analyzed, evaluated, and optimized more efficiently, objectively, and precisely based on this new technology. The training sequence parallel detection technology could be a 'perspective instrument' for GSM cellular radio network.

\subsection{Timeslot measurement used in 3/4G network}

The training sequence parallel detection technology base on timeslot sliding window proposed in this paper could be expanded and used in the channels timeslot measurement of 3/4G cellular radio network. The Time Division Synchronous Code Division Multiple Access (TD-SCDMA) time frames, time slots, and bursts structure appear in Figure 4 [14], where $T_{\mathrm{c}}=12.5 / 16 \mu \mathrm{s}$ denotes the chip duration; cyclic prefix (CP) denotes the chip length; chips denote the number of the chips.

The training sequence in TD-SCDMA burst structure is also called midamble code, which is used in channel estimation, synchronization maintaining, power measurement, etc.

The midamble codes have a length of 144 chips, which are generated by basic midamble codes though cycle extension. The basic midamble codes have a length of 128 chips in TD-SCDMA system. TD-SCDMA system has 128 basic midamble codes, which are divided into 32 groups of four. Each cell is allocated basic midamble codes in a group. The midamble codes used by different users in a timeslot are generated by the cell's basic midamble codes though cyclic shift in a serving cell [15].

TD-SCDMA system is a uplink and downlink synchronization system [16]. For the normal timeslot, the parallel detection of the traffic channelization codes' burst midamble could be realized based on sliding timeslot window. A midamble codes parallel detection technology based on sliding timeslot window is shown in Figure 5.

There is one to one corresponding relationship between the downlink pilot codes and the basic midamble codes group in TD-SCDMA system. For one specific normal timeslot in one carrier frequency, the number of users is equal to the cyclic shift phase number of basic midamble codes. The midamble codes in one burst have no spreading and scrambling process, so the midamble codes are a definite signal. And the midamble codes and the data symbols have the same transmission power in one traffic burst [17]. On this basis, the signal power and $\mathrm{C} / \mathrm{I}$ of the different phase shifts of different basic 


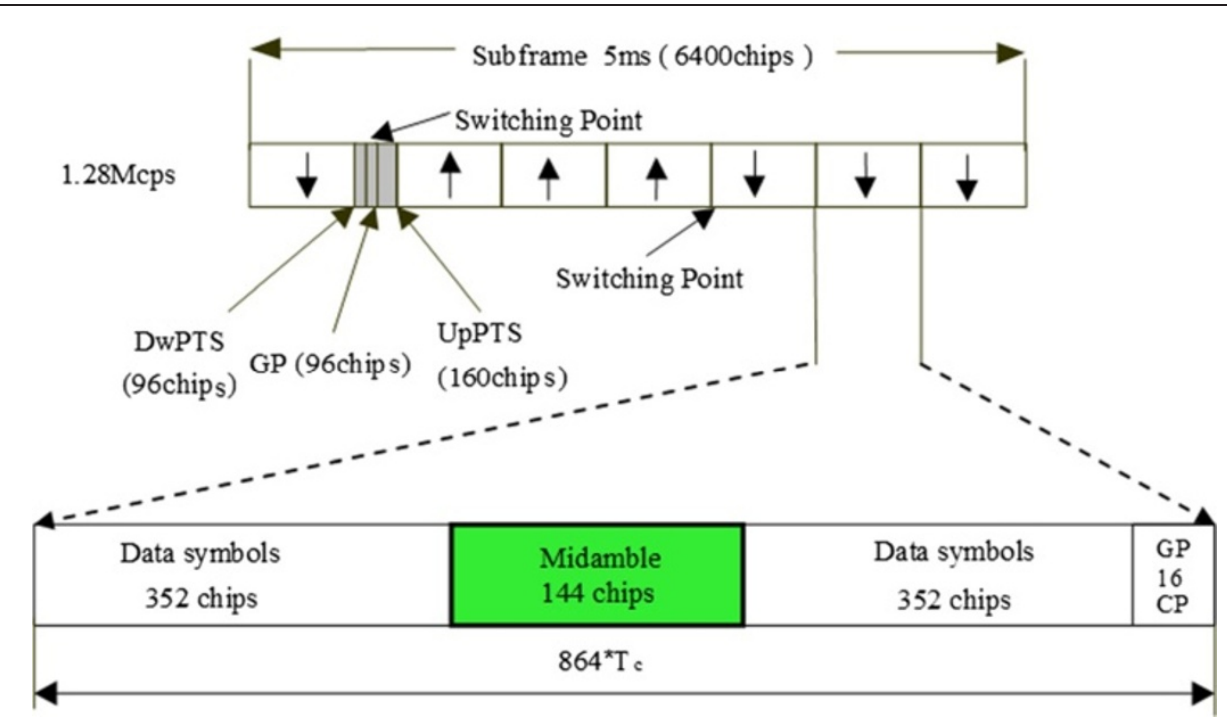

Figure 4 TD-SCDMA time frames, time slots, and bursts structure.

midamble codes, which may be from different cochannel cells, could be measured using the midamble codes parallel detection technology based on timeslot sliding window proposed in this paper. These measurement data could be used to analyze the coverage and interference condition between co-channel cells precisely, which could provide scientific basis to the high efficient optimization of the TD-SCDMA cellular radio network.

For the 4G Long Term Evolution (LTE) network, its physical layer is based on orthogonal frequency division multiplexing (OFDM) with a cyclic prefix (CP) in the downlink [18]. Cell-specific reference signals (CRS) are equivalent to training sequence in $2 / 3 \mathrm{G}$ network. CRS are transmitted in all downlink subframes in a cell supporting
Physical Downlink Shared Channel (PDSCH) transmission [19], which have a fixed position in time domain and frequency domain. Therefore, the reference symbol (RS) received power (RSRP) and signal to interference plus noise ratio (SINR) of the co-channel signals from different cells could be distinguished and measured by parallel detection of the CRS based on timeslot, which provides a scientific and efficient measurement means for the interference and coverage analysis and their optimization in LTE cellular radio network.

\section{Application of timeslot measurement}

4.1 Timeslot measurement data

The training sequence parallel detection technology base on timeslot sliding window proposed in this paper has

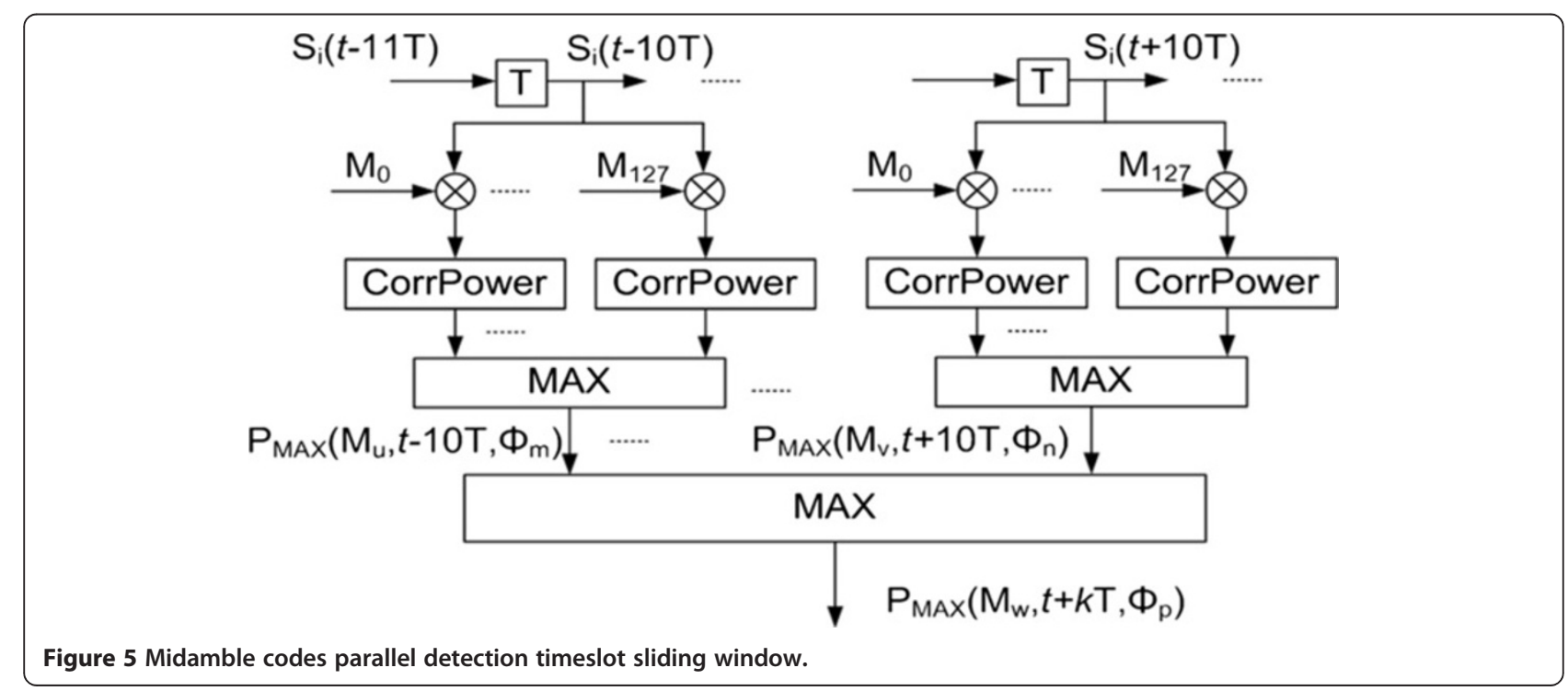


already been developed and realized in the frequency scanner. Also, this kind of timeslot measurement is called as the high accurate traffic channel timeslot scanning.

The high accurate traffic channel timeslot scanning data have been used for Zhejiang mobile communication system daily optimization engineering of positioning problems of interference, evaluating the radio networks' noise floor and rationality of carrier frequencies' coverage, which has achieved the desired results. Table 1 shows the traffic timeslot measurement data. Figure 6a shows the training sequence codes' power measurement of each timeslot for different frequency. Figure $6 \mathrm{~b}$ presents the C/I measurement of each training sequence code for each timeslot and different frequency. For each BCCH frequency, both measurement results from training sequence detection match very well with the Frequency Correction Channel (FCCH) measurement with a traditional $\mathrm{BCCH}$ frequency scanner. This means that the training sequence parallel detection technology base on timeslot sliding window proposed in this paper is a perfect way to measure both $\mathrm{BCCH}$ and $\mathrm{TCH}$ timeslots.

\subsection{Conjoint analysis with timeslot measurement data}

By two kinds of timeslot measurement with difference training sequence code allocation by each cell, combined with layer 3 location area code (LAC) and cell identification (CI) decoding of all $\mathrm{BCCH}$ channels scanning from the same measuring point, the same carrier frequency transmitted power, and C/I condition coming from different cells can be located.

The high accurate traffic timeslot scanning equipment usually is used with drive test equipment in the same car in the practical engineering application, so that it may synchronously measure the traffic timeslot signal occupied by drive test equipment. At the same time, these two measuring data can be analyzed jointly. Figure 7 shows the key technique process of conjoint analysis for high accurate traffic timeslot scanning

Table 1 Traffic timeslot measurement data

\begin{tabular}{|c|c|c|c|c|c|c|c|c|c|}
\hline $\begin{array}{c}\text { System date } \\
\text { time }\end{array}$ & Longitude & Latitude & $\begin{array}{l}\text { Frequency } \\
\text { channel ID }\end{array}$ & $\begin{array}{l}\text { Time slot } \\
\text { number }\end{array}$ & $\begin{array}{l}\text { Time slot power } \\
(\mathrm{dBm})\end{array}$ & $\begin{array}{c}\mathrm{C} / \mathrm{I} \\
(\mathrm{dB})\end{array}$ & $\begin{array}{c}\text { TSC correlation } \\
\text { power }(\mathrm{dBm})\end{array}$ & $\begin{array}{c}\text { Time offset } \\
(\mu \mathrm{s})\end{array}$ & TSC \\
\hline $\begin{array}{c}2013 / 4 / 22 \\
15: 24: 02.390\end{array}$ & 120.14342 & 30.26115 & 3 & 0 & -85.25 & -6.71 & -92.63 & -6 & 2 \\
\hline $\begin{array}{c}2013 / 4 / 22 \\
15: 24: 02.390\end{array}$ & 120.14342 & 30.26115 & 3 & 1 & -79.57 & 3.21 & -81.54 & 0 & 2 \\
\hline $\begin{array}{c}2013 / 4 / 22 \\
15: 24: 02.390\end{array}$ & 120.14342 & 30.26115 & 3 & 2 & -80.21 & -3.57 & -84.957 & -5 & 0 \\
\hline $\begin{array}{c}2013 / 4 / 22 \\
15: 24: 02.390\end{array}$ & 120.14342 & 30.26115 & 3 & 3 & -80.52 & -5.14 & -86.277 & -2 & 0 \\
\hline $\begin{array}{c}2013 / 4 / 22 \\
15: 24: 02.390\end{array}$ & 120.14342 & 30.26115 & 3 & 4 & -81.27 & -4.44 & -86.51 & 10 & 0 \\
\hline $\begin{array}{c}2013 / 4 / 22 \\
15: 24: 02.390\end{array}$ & 120.14342 & 30.26115 & 3 & 5 & -80.38 & -4.96 & -85.65 & -10 & 7 \\
\hline $\begin{array}{c}2013 / 4 / 22 \\
15: 24: 02.390\end{array}$ & 120.14342 & 30.26115 & 3 & 6 & -88.03 & -6.71 & -96.65 & -3 & 6 \\
\hline $\begin{array}{c}\text { 2013/4/22 } \\
15: 24: 02.390\end{array}$ & 120.14342 & 30.26115 & 3 & 7 & -87.74 & -6.55 & -95.73 & -6 & 5 \\
\hline $\begin{array}{c}2013 / 4 / 22 \\
15: 24: 02.390\end{array}$ & 120.14342 & 30.26115 & 4 & 0 & -77.52 & 14.27 & -78.18 & 0 & 0 \\
\hline $\begin{array}{c}\text { 2013/4/22 } \\
15: 24: 02.390\end{array}$ & 120.14342 & 30.26115 & 4 & 1 & -76.64 & 7.78 & -78.38 & 0 & 0 \\
\hline $\begin{array}{c}\text { 2013/4/22 } \\
15: 24: 02.390\end{array}$ & 120.14342 & 30.26115 & 4 & 2 & -76.29 & 2.17 & -78.59 & 0 & 7 \\
\hline $\begin{array}{c}2013 / 4 / 22 \\
15: 24: 02.390\end{array}$ & 120.14342 & 30.26115 & 4 & 3 & -77.6 & 5.08 & -80.32 & 0 & 7 \\
\hline $\begin{array}{c}2013 / 4 / 22 \\
15: 24: 02.390\end{array}$ & 120.14342 & 30.26115 & 4 & 4 & -76.56 & 1.41 & -78.02 & 0 & 7 \\
\hline $\begin{array}{c}2013 / 4 / 22 \\
15: 24: 02.390\end{array}$ & 120.14342 & 30.26115 & 4 & 5 & -76.32 & 7.65 & -77.37 & 0 & 7 \\
\hline $\begin{array}{c}2013 / 4 / 22 \\
15: 24: 02.390\end{array}$ & 120.14342 & 30.26115 & 4 & 6 & -77.52 & -9.76 & -87.38 & -2 & 2 \\
\hline $\begin{array}{c}2013 / 4 / 22 \\
15: 24: 02.390\end{array}$ & 120.14342 & 30.26115 & 4 & 7 & -76.78 & 11.25 & -77.61 & 0 & 0 \\
\hline
\end{tabular}


(a) Timeslot power measurement

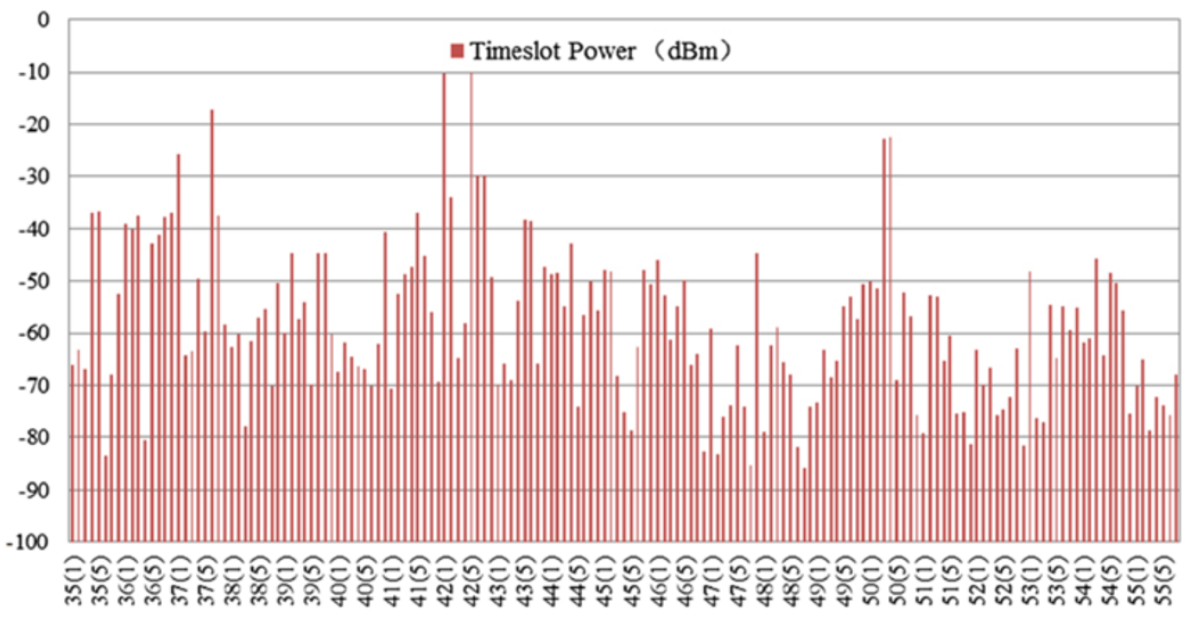

(b) Timeslot $\mathrm{C} / \mathrm{I}$ measurement

n Timeslot $\mathrm{C} / \mathrm{I}(\mathrm{dB})$

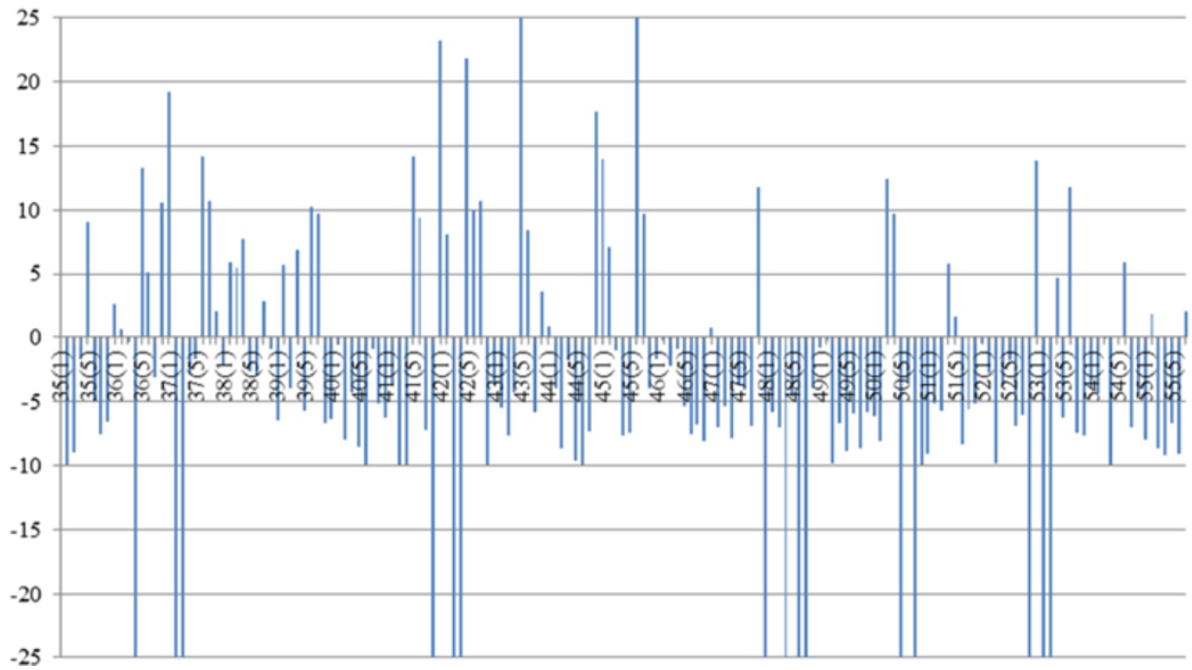

Figure 6 Timeslot power measurement (a) and timeslot C/I measurement (b).

frequency and drive test data. The analysis of key process is illustrated below:

(1)Locating serving cells having problems

The serving cell occupied by the present drive test terminal's traffic can be located from test data of drive test which having problems of Rx-Quality Sub, which means the serving cell having problems.

(2) Coverage analysis of problem cells

From 'TSC' field and 'Correlation Power' field in the timeslot table of high accurate traffic timeslot scanning data, the coverage signal power level of the present frequency's traffic timeslot can be checked. It can be analyzed and estimated whether the present receipted signal's bad Rx-Quality Sub is caused by weak coverage. If the max TSC Correlation Power of serving cells in the test road bad Rx-Quality problem section is lower than $-85 \mathrm{dBm}$, then the problem of weak coverage needs selective analysis. Moreover, the cross-boundary coverage problem can be estimated by considering the distance of the test point of section having problems and the site location of serving cell.

(3) Interference analysis of problem cells

If the coverage power level of the serving cell frequency in the timeslot table (such as Table 1) is normal (for example, TSC Correlation Power $>-85$ $\mathrm{dBm}), 0<\mathrm{C} / \mathrm{I}<9$ at the same time, then the interference situation of this frequency exists. 


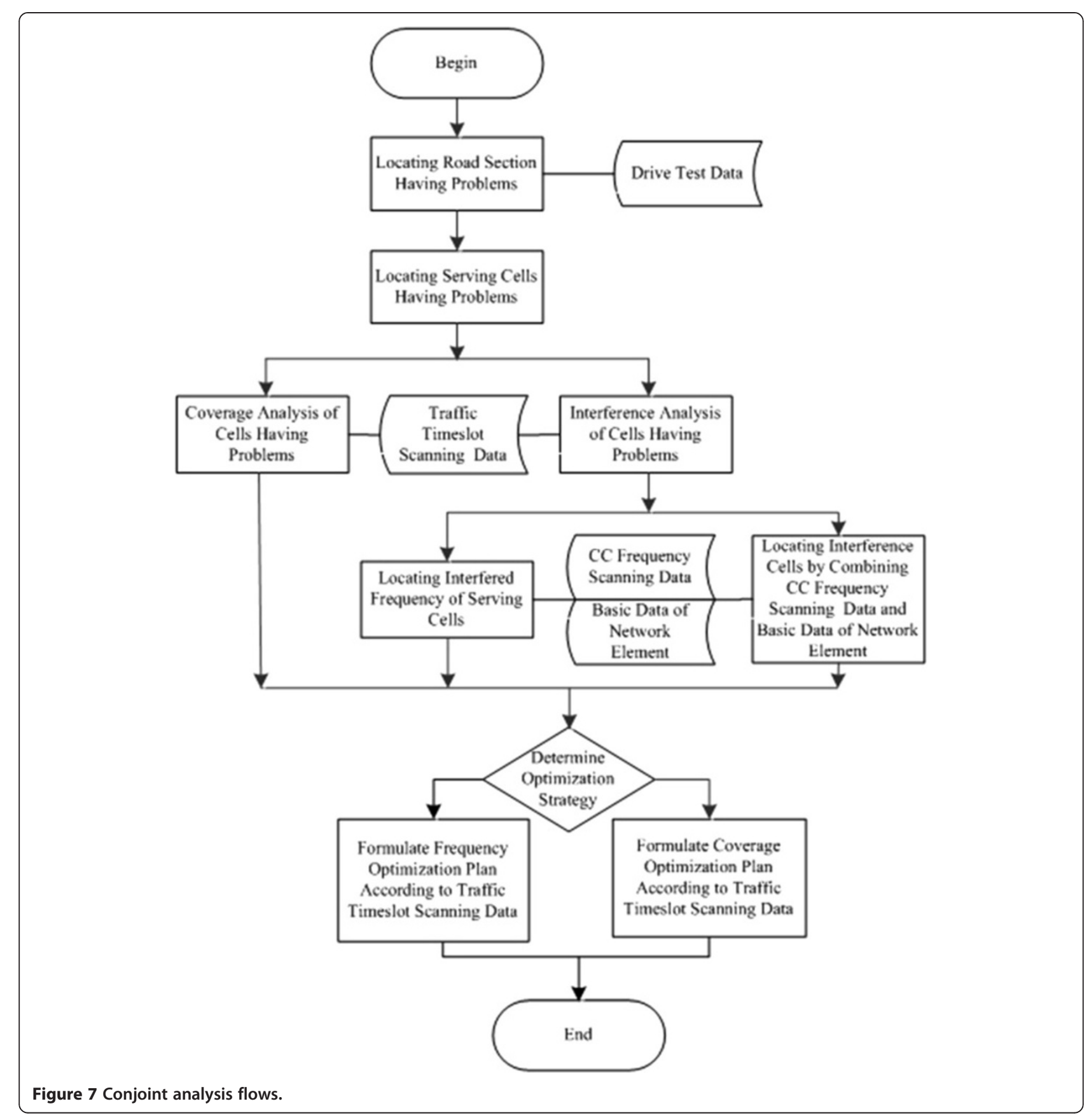

(4) Locating interfered frequency

For a serving cell's every frequency of the road section having bad Rx-Quality problems, the C/I value of the serving cell's each $\mathrm{TCH}$ timeslot can be viewed from the 'C/I' field in the timeslot table. If the TSC related with the max TSC correlation power is not the TSC of the current serving cell $(\mathrm{C} / \mathrm{I}>0)$, then the value of TSC correlation power is the reception signal level from co-channel interference cells. In addition, the value of $\mathrm{C} / \mathrm{I}$ is the $\mathrm{C} / \mathrm{I}$ of receipt signal that belongs to co-channel interference cells in the test point having bad Rx-Quality problem.

(5)Locating interfering cells

If a frequency of a serving cell is interfered in the specified road section having bad Rx-Quality problem, the co-channel interference cell interfering the same channel of the serving cell needs to be analyzed and located. The location algorithm of interfering cells is shown below: 
First, consider the traditional $\mathrm{BCCH}$ frequency scanning data of this road section (scanning data table of $\mathrm{BCCH}$ frequency) to ensure the cells set $\mathrm{B}$, coverage overlap cells set in this problem region. Second, for the specified interfered carrier frequency of the serving cell in the problem road section, analyze the timeslot table to seek the co-channel interference cells whose TSC belongs to other cells. Check the cells set A having co-channel but different TSC within coverage overlap cells set B. The cells set A contains interference cells interfering the problem serving cell. For the attention, the probability of existing cells having the co-channel and the same TSC in the cells set $B$ is very small. If it really happens, accurate location of the real interference cell can be performed according to the azimuth angle of cells and distances between cells and the test point of road section having bad Rx-Quality problems.

(6) Locating reason of road section having problems According to high accurate traffic timeslot scanning measurement data, the situation of received signal level and C/I for each cell's each carrier frequency's each timeslot of the road section having bad Rx-Quality problems can be checked from the analysis above. Whether the coverage of cells is reasonable can be analyzed with a map. If the received signal level by the drive test equipment in the road section having bad Rx-Quality problems from a farther cell is very strong, then it means the coverage of this cell is not reasonable. The antenna of this cell needs to adjust to control the problem of crossboundary coverage. If the road section having bad RxQuality problems is strongly interfered by the nearby cell, then it explains that the frequency assignment is not reasonable. It needs frequency optimization.

The conjoint analysis technology of high accurate traffic timeslot scanning measurement and drive test has been applied in the pilot program of China Mobile Ltd in Zhejiang Province. The Beishan Road near the West Lake in Hangzhou that existed bad Rx-Quality Sub problems for a long term was conjointly analyzed by the synchronization test of traffic timeslot scanning measurement data and drive test data. Plenty of problems of coverage and interference were accurately located, which means the remarkable engineering application is effective.

As shown Figure 8, the no. 54 frequency of no. 30984 cell located by timeslot scanning data analysis in the bad quality section of Beishan Road in Hangzhou is severely interfered by several the same frequency cells with no. 54 frequency around it, so the statistic C/I of no. 54 frequency in no. 30984 cell is only 5.47. In addition, according to the analysis of timeslot scanning data for this section, the received power of no. 68 frequency is relatively small. It means its multiplexing density in this

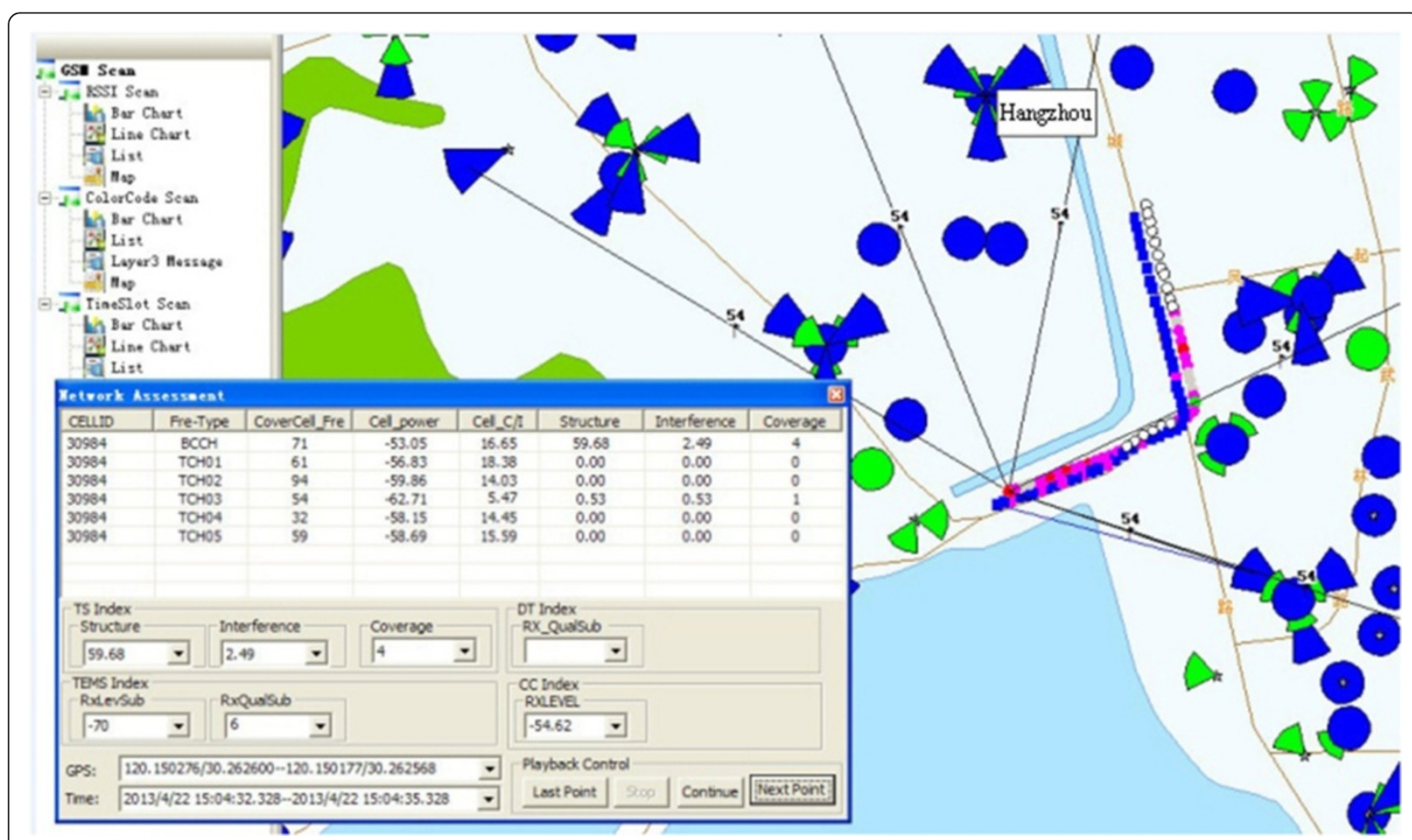

Figure 8 Traffic timeslot measurement locating interference cells. 
section is relatively low, so it is suited to replace the no. 54 frequency of no. 30984 cell, to improve the signal quality for this measurement point.

Timeslot measurement supplies direct measuring technological means for frequency coverage condition analysis, noise floor analysis, interference condition and locating of interference source analysis, radio network structure analysis, etc. Timeslot measurement offers the most important radio measuring technological means for precise optimization and the improvement of radio networks' performance.

\subsection{Network structure analysis}

Using the high accurate traffic channel timeslot scanning measurement data to evaluate radio network structure mainly can perform assessments such as frequency number of road overlapping coverage, TRX (carrier frequency transceiver) number of road overlapping coverage, frequency complexity of roads, and frequency reuse density of roads. Among these assessments, the same frequency is reused for $n$ different cells means existing $n$ TRX of cochannel interference in the overlapping coverage region. The theoretical available frequency number of radio network is set as $M$.

Definition. Frequency number of road overlapping coverage $N_{F_{-} \text {overlap }}\left(g_{q}\right)$ is the $(\mathrm{BCCH}+\mathrm{TCH})$ frequency sum of all cells measured by the high accurate traffic channel timeslot scanning equipment in the specified testing road grid $g_{q}$ when it is lower than the strongest signal $R_{P \max }=35 \mathrm{~dB}$ or higher than the received power $P_{\text {low }}=-85 \mathrm{dBm}$.

$$
N_{F_{-} \text {overlap }}\left(g_{q}\right)=\text { count }\left[i,<f_{i}, g_{q}>\right]
$$

The function count [•] denotes counting different elements conforming to the condition $<\bullet>$ in brackets.

Definition. Frequency complexity of $\operatorname{road} \operatorname{FCR}\left(g_{q}\right)$ is the result of frequency number of roads overlapping coverage $N_{F_{-} \text {overlap }}\left(g_{q}\right)$ divided by theoretical available frequency number $\mathrm{M}$ and multiplied by $100 \%$.

$$
\operatorname{FCR}\left(g_{q}\right)=N_{F \_ \text {overlap }}\left(g_{q}\right) / \mathrm{M} \times 100 \%
$$

Definition. TRX number of road overlapping coverage $N_{\text {TRX_overlap }}$ is the combinatorial number (frequency + TSC) measured by the high accurate traffic channel timeslot scanning equipment in the specified testing road grid $g_{q}$ when it is lower than the strongest signal level $R_{P \max }=$ $35 \mathrm{~dB}$ or higher than the received power $P_{\text {low }}=-80 \mathrm{dBm}$.

$$
N_{\text {TRX_overlap }}\left(g_{q}\right)=\text { count }\left[\mathrm{C}(i, j)<f_{i}\left(\mathrm{TSC}_{j}\right), g_{q}>\right]
$$

Definition. Frequency reuse density of roads $\rho_{F}\left(g_{q}\right)$ equals TRX number of road overlapping coverage divided by frequency number of road's overlapping coverage measured by the high accurate traffic channel timeslot scanning equipment.

$$
\rho_{F}\left(g_{q}\right)=N_{\text {TRX_overlap }}\left(g_{q}\right) / N_{F \_ \text {overlap }}\left(g_{q}\right)
$$

Definition. Single frequency reuse density $\rho_{F}\left(f_{i}, g_{q}\right)$ is the TRX number of road overlapping coverage of the same carrier frequency $f_{i}$ having different TSC measured by the high accurate traffic channel timeslot scanning equipment in the specified testing road grid $g_{q}$. It is equal to co-channel cells number of $f_{i}$ existing correlative traffic.

$$
\rho_{F}\left(f_{i}, g_{q}\right)=\operatorname{count}\left[\nu,<f_{i}\left(\mathrm{TSC}_{v}\right), g_{q}>\right]
$$

Single frequency reuse density index can be used to screen the corresponding frequency set whose frequency reuse density is too high in interference road section having problems. Moreover, it is used to perform frequency optimization adjustment by screening lower reuse density frequencies.

The performance of radio network structure could be evaluated objectively and accurately, by using five defined network structure indices above, such as performing alerting when frequency complexity of road (FCR) $\left(g_{q}\right)$ is larger than $75 \%$, and optimization adjustment is needed when FCR $\left(g_{q}\right)$ is larger than $100 \%$; performing alerting when frequency reuse density of road is larger than 1.5, and optimization adjustment is needed when frequency reuse density of roads is larger than 2 .

The correlation analysis index of network structure proposed in this paper was performed analysis validation in Hangzhou, Zhejiang. The result shows that the analysis is efficient and precise. In the interference road section having level 6 and level 7 Rx-Quality Sub of Beishan Road West Lakeside Hangzhou shown in Figure 9 (the section of rad circles pointed by arrows and the blue triangles and circles in Figure 9 marks the sites of GSM at $900 \mathrm{MHz}$ outdoor cells and indoor cells, respectively; the green triangles and circles in Figure 9 mark the sites of Digital Cellular System at 1,800 MHz outdoor cells and indoor cells, respectively), the corresponding FCR is larger than $90 \%$. In addition, frequency reuse density of roads is larger than 2 (shown in Figure 10). The radio network structure is complex, which induces the obvious frequency interference problems in the system.

According to the contrastive analysis of Figures 6 and 7, the traffic testing bad Rx-Quality Sub road section, high interference road section, and the road section of complex network structure present good correlation. In addition, the key cell and key carrier frequency causing problems of network structure can be accurately located by carrier class timeslot measuring of high accurate traffic timeslot scanning, which supplies objectives and accurate basis for 


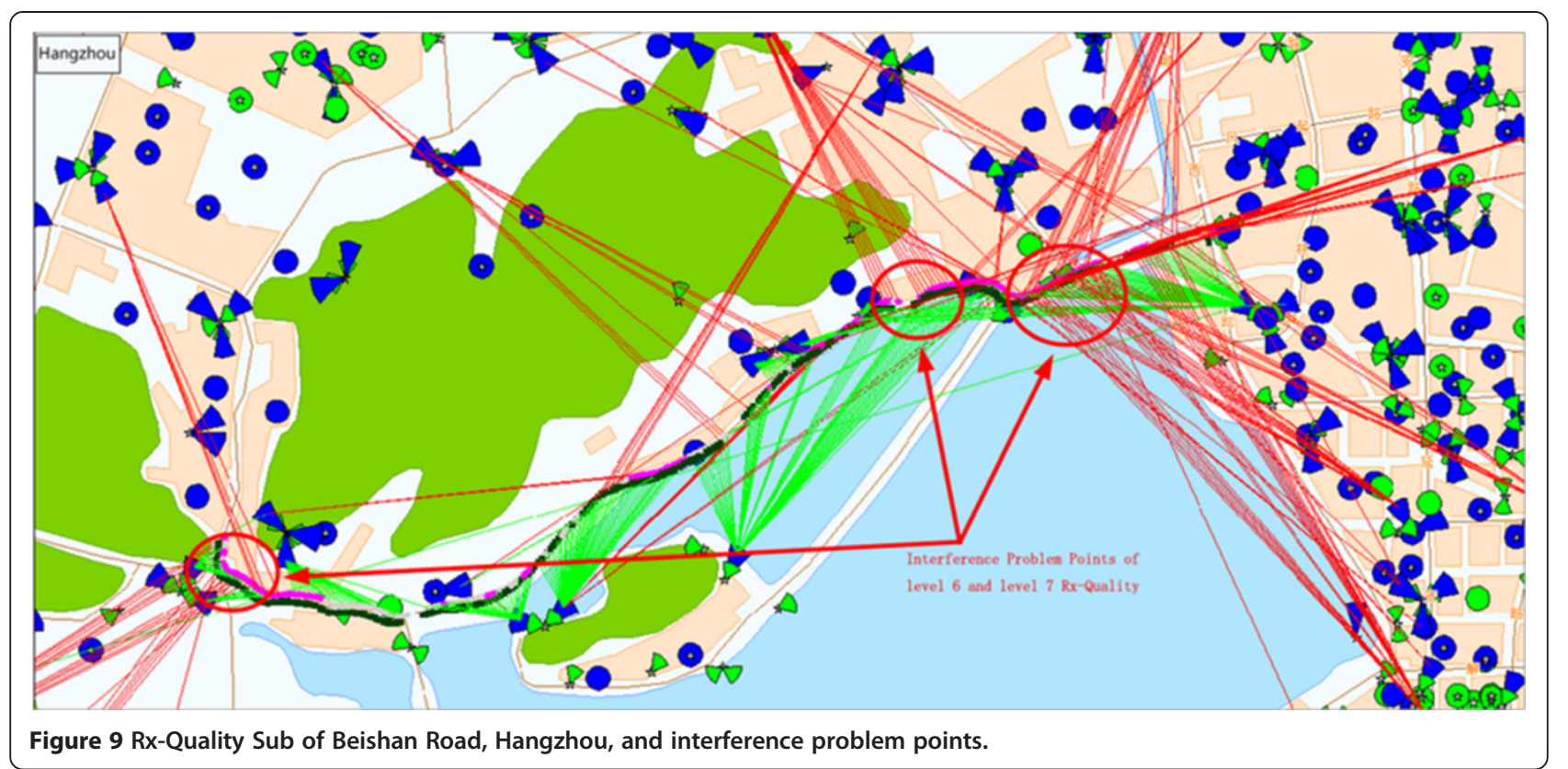

targeted efficient optimization of structure problems. It surmounts the subjectivity, inaccuracy, and uncertainty analysis based on traditional $\mathrm{BCCH}$ frequency scanning measuring being equivalent to $\mathrm{TCH}$ frequency measuring. It also makes the network structure assessment turn into accurate actual measurement phase from traditional inaccurate estimation phase.
On the basis of performing objective analysis for network structure, combining the coverage analysis and interference analysis based on high accurate traffic channel timeslot scanning to perform exquisite and integrated optimization for radio network can furthest excavate and improve the potential performance of radio network.

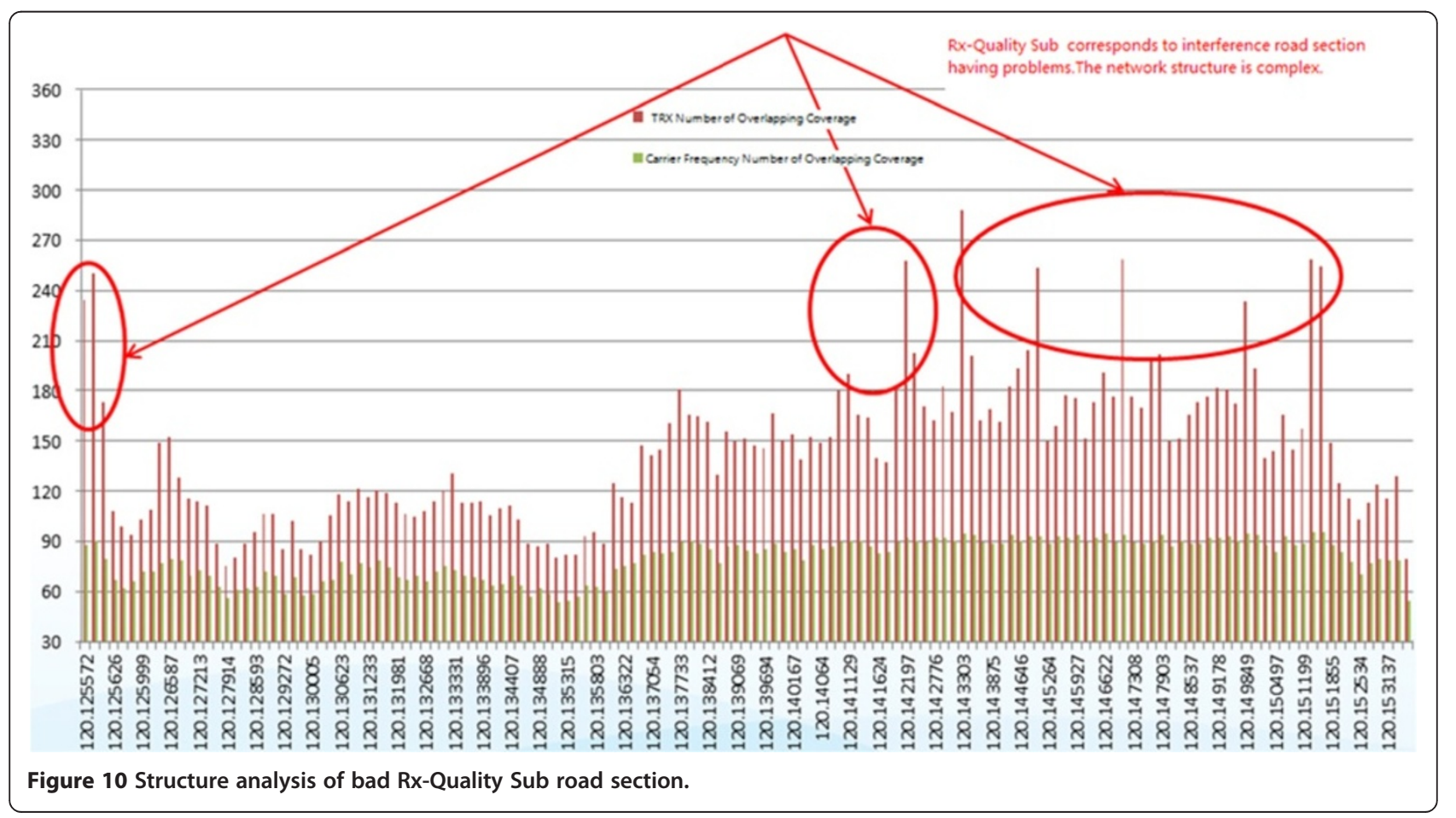




\section{Conclusions}

The training sequence parallel detection technology base on timeslot sliding window proposed in this paper is a significant innovation of frequency scanning technology. Moreover, its idea could also be applied to the radio networks measurement of $3 \mathrm{G}$ and $4 \mathrm{G}$ cellular mobile communication systems, which has indispensable core value of application for planning and optimizing engineering's accurate analysis of radio network problems and provision of high efficient solution.

\section{Endnotes}

${ }^{a}$ It should be noted that our training sequence parallel detection technology based on timeslot sliding window is used for downlink power level and C/I measuring, which could distinguish co-channel signal from different overlay coverage cells.

${ }^{\mathrm{b}}$ The research on the training sequence detection in this paper is aimed at $\mathrm{TCH}$ timeslot measuring, and the measurement data would be used to analyze and optimize the performance of cellular radio network.

\footnotetext{
Abbreviations

ACl: adjacent channel interference; BCCH: Broadcast Channel; CC: color code; CCl: co-channel interference; CDMA: Code Division Multiple Access; Cl: cell identification; CRS: cell-specific reference signal; CP: cyclic prefix; C/I: carrier interference ratio; DTX: discontinuous transmission; DwPTS: downlink pilot time slot; FCCH: Frequency Correction Channel; GMSK: Gaussian filtered minimum shift keying; GP: guard period; GSM: Global System for Mobile communication; LTE: Long Term Evolution; OFDM: orthogonal frequency division multiplexing; PDSCH: Physical Downlink Shared Channel; RACH: Random Access Channel; RS: reference signal; RSRP: RS received power; Rx: reception; SNR: signal-to-noise ratio; TCH: traffic channel; TDMA: time division multiple access; TD-SCDMA: Time Division Synchronous CDMA; TRX: transmission and reception; TSC: training sequence code; UpPTS: uplink pilot time slot.
}

\section{Competing interests}

The authors declare that they have no competing interests.

\section{Acknowledgements}

The research project base on network structure evaluating technology of frequency scanning from this paper was highly valued and strongly supported by leaders and staff of China Mobile Communications Corporation and China mobile Zhejiang branch. Thanks to them for the smooth establishment of and good results obtained from this research project!

\section{Author details}

'School of Electronic Information Engineering, Tianjin University, Tianjin 300072, China. ${ }^{2}$ School of Telecommunications Engineering, Beijing University of Posts and Telecommunications, Beijing 100876, China.

Received: 7 January 2014 Accepted: 30 June 2014 Published: 16 July 2014

\section{References}

1. H Zheng, $\mathrm{F}$ Chen, A radio network structure evaluating technology base on frequency scanning. Telecommun Technol J 8, 74-79 (2013)

2. KH William, Frequency assignment: theory and applications. Proc. IEEE 68, 1497-1514 (1980)

3. KN Sivarajan, M Celiece RJ, JW Ketchun, Channel assignment in cellular radio network. Proc. IEEE 39th VTC, 846-850 (1989)

4. R Mathar, J Mattfeldt, Channel assignment in cellular radio networks. IEEE Trans Veh Technol 42(4), 647-656 (1993)
5. N Mijatovic, I Kostanic, G Evans, Use of scanning receivers for RF coverage analysis and propagation model optimization in GSM networks, in European Wireless Conference, 2008, pp. 1-6

6. N Mijatovic, I Kostanic, S Dickey, Comparison of receive signal level measurement techniques in GSM cellular networks, in IEEE CCNC, 2008, pp. 738-743

7. ZH Jiang, W Hong, L Tian, Design of a triple-band scanner for TD-SCDMA network planning and optimization, in International Conference on Communication Technologie, 2010, pp. 1220-1223

8. H Zhao, C Song, S Zhang, Implementation and performance analysis of channel estimation in TD-SCDMA. Mod Electron Tech J 5, 86-96 (2005)

9. S Qinfang, DC Cox, A Lozano, HC Huang, Training-based channel estimation for continuous flat fading BLAST, in IEEE International Conference on, Volumel, 28 April-2 May 2002, 2002, pp. 25-329

10. M-H Hsieh, C-H Wei, Channel estimation for OFDM systems based on comb-type pilot arrangement in frequency selective fading channels. IEEE Trans Comsumer Electron 44(1), 217-255 (1998)

11. GSM Technical specifications 05.01, Physical layer on the radio path. Version 7.0.1 release, ETSI, phase 2+, 1998.

12. GSM Technical specifications 05.02, Multiplexing and multiple access on the radio path. Version 7.1.0 release, ETSI, phase $2+, 1998$.

13. GSM Technical specifications 03.03, Numbering, addressing and identification. Version 7.1.0 release, ETSI, phase 2+, 1998.

14. 3GPP Technical specifications 25.221, Physical channels and mapping of transport channels onto physical channels (TDD). Version 7.6.0 release, 3GPP, TSGRAN, 2009

15. SH Li, The Three Generation Mobile Communication System Standards TD-SCDM (People's Posts and Telecommunications Press, Beijing, 2003), pp. 53-54

16. 3GPP Technical specifications 25.201, Physical layer-general description. Version 7.b.0 release, 3GPP, TSGRAN, 2009.

17. MG Peng, WB Wang, TD-SCDMA Mobile Communication System, 2nd edn. (Machinery Industry Press, Beijing, 2005), p. 69

18. 3GPP Technical specifications 36.201 V9.1.0, Evolved Universal Terrestrial Radio Access (E-UTRA); LTE physical layer, 2010-03.

19. 3GPP Technical specifications 36.211 V9.1.0, Evolved Universal Terrestrial Radio Access (E-UTRA): Physical Channels and Modulation, 2010-03.

doi:10.1186/1687-1499-2014-119

Cite this article as: Shi et al:: A training sequence parallel detection technology based on timeslot sliding window. EURASIP Journal on Wireless Communications and Networking 2014 2014:119.

\section{Submit your manuscript to a SpringerOpen ${ }^{\circ}$ journal and benefit from:}

- Convenient online submission

- Rigorous peer review

- Immediate publication on acceptance

- Open access: articles freely available online

- High visibility within the field

- Retaining the copyright to your article

Submit your next manuscript at $>$ springeropen.com 